\title{
Clinical Application of Gold Nanoparticles for Diagnosis and Treatment
}

Seung-Kuk Baek

Department of Otorhinolaryngology-Head and Neck Surgery, Korea University College of Medicine, Seoul, Korea
Received May 7, 2021

Accepted June 7, 2021

\section{Correspondence}

Seung-Kuk Baek

Department of Otorhinolaryngology-Head and Neck Surgery, Korea University College of Medicine, 73 Goryeodae-ro, Seongbuk-gu, Seoul 02841, Korea

Tel.: +82-2-920-5486

Fax: +82-2-925-5233

E-mail: mdskbaek@gmail.com

(C) Korean Society for Laser Medicine and Surgery

(c) This is an open access article distributed under the terms of the Creative Commons Attribution NonCommercial License (http://creativecommons.org/ licenses/by-nc/4.0) which permits unrestricted noncommercial use, distribution, and reproduction in any medium, provided the original work is properly cited.
Advances in nanobiotechnology have presented numerous possibilities of more effective diagnostic and therapeutic options. In particular, gold nanoparticles have demonstrated the potential for application in molecular imaging and treatment of cancers, including drug delivery system of certain target molecules, enhancement of radiation therapy, and photothermal treatment. This review discusses the properties, mechanism of action, and clinical application of gold nanoparticles. Although the safety of nanoparticles is yet to be ascertained, there is no doubt that in the future, nanotechnology will play an important role in the development and enhancement of a wide range of diagnostic and treatment modalities.

\section{Key words}

Nanoparticles; Drug delivery systems; Laser therapy; Gold 


\section{INTRODUCTION}

Nanotechnology is a representative of fusion research and fusion technologies, born from the interdisciplinary fusion of several scientific fields such as chemistry, physics, engineering, and molecular biology. The development of nanotechnology has opened new doors of application, among them, the integration of nanoparticles into biology. Nanoparticles exhibit unique structural, chemical, biological, mechanical, electrical, and magnetic properties, which allow a wide range of applications in the field of biomedicine. ' Currently, nanotechnology potential applications in biomedicine include drug delivery, ${ }^{2-4}$ diagnosis including cancer cells, ${ }^{5-8}$ and therapeutic including cancer treatment. 9.10

Nanoparticles are categorized based on their composition; gold, iron oxide, carbon, dielectric materials, and liposomes, and shape; solid nanoparticles, nanoshells, nanocages, Nanowires and nanotubes. ${ }^{11}$ Gold nanoparticles are among the nanometerials with high potential for application in the biomedicine field. They are easily produced in multiple nanoparticles that exhibit multiple surface functionalities, have versatile surface chemistry properties, are relatively biocompatible, and have low toxicity. ${ }^{11-15}$ These unique properties open many possibilities for their application making them the first choice for researchers in the biomedicine field. Currently, there are ongoing research studies on gold nanoparticles application in intravascular drug delivery, and gene transmission, ${ }^{16}$ photothermia, ${ }^{9,11}$ and ionizing radiation enhancement. ${ }^{17,18}$ Although nanotechnology, in general, is relatively necessary to be prove its feasibility and safety, it is a field that has enormous potential with a lot to be explored. The clinical trials on the application of gold nanoparticles in head and neck cancer is a major milestone, in addition, our experience thus far has enabled us to discover more possible applications than we had hypothesized. In the future, more research including the use of gold nanoparticles should be performed in otolaryngology. Herein, I present the potential of nanotechnology application in biomedicine.

\section{FEATURE OF GOLD NANOPARTICLES}

Unique optical and physical properties of gold nanoparticles as well as its tailored surface functionalization provide an opportunity for developing cancer theragnostics through different mechanisms. ${ }^{2}$ First, when nano-sized particles are injected into the body, a large number of particles accumulate in the tumor cells enabling tumor tracking and clear identification, and high drug uptake and penetration into the tumor. Second, because gold nanoparticles respond to light of a specific wavelength, it is possible to take images of both the tumor and tumor cells; In addition, their ability to dissipate heat from the particle surface facilitates hyperthermal treatment. These mechanisms underlie simultaneous therapeutic and diagnostic applications.

\section{GOLD NANOPARTICLES OPTICAL PROPERTIES USEFUL FOR CELL IMAGING}

\section{Surface plasmon resonance}

When gold nanoparticles are stimulated by external light, the phenomenon that the conduction band electrons on the surface of the particles vibrate on the surface of the particles and collide with each other is called surface plasmon resonance (SPR). Gold nanoparticles irradiated by light show two reactions to the energy received from light: light scattering and light absorption. Light scattering is a phenomenon that energy received from light excites electrons on the surface of a particle vibrates and light of the same wavelength is emitted; light absorption is that the absorbed energy is converted into heat. In particular, nanoparticles have a characteristic maximum wavelength, "Peak frequency", at which light is absorbed and scattered, and it is dependent on size, shape, composition, and surrounding environment. This wavelength can be tuned to the visible and infrared regions with appropriate size and shape changes (Fig. 1). By utilizing such characteristics, it is possible to produce nanoparticles with a high level of sensitivity at a specific wavelength, applicable

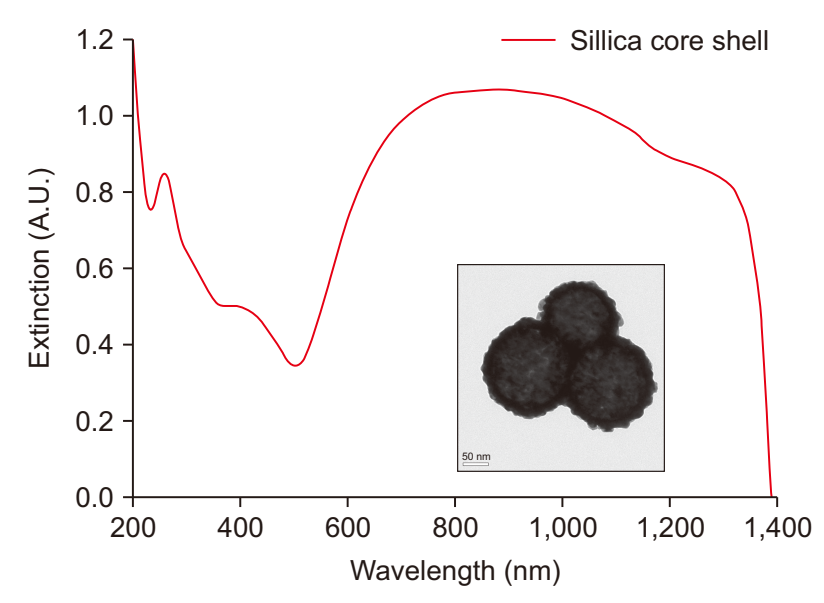

Fig. 1. Light absorption spectrum of gold nanoshell with a $120 \mathrm{~nm}$ silica core with 12-15 $\mathrm{nm}$ gold shell and transmission electron microscopy feature of gold nanoshell (small box). 
in imaging of cancer cells and photothermal treatment. Therefore, the concept of utilizing optical properties of the gold nanoparticles such as light scattering, light absorption, and surface plasmon resonance can make promising platforms for a wide range of technologies including fluorescence, ${ }^{18}$ photo-absorption and -scattering, ${ }_{1}^{19}$ photoacoustic imaging, ${ }^{20}$ and surface-enhanced Raman scattering (SERS). ${ }^{21,22}$

\section{Fluorescent image of gold nanoparticles}

Surface plasmon resonance can modify the optical properties of materials close to the nanoparticles. Thus, when gold nanoparticles bind to a substance, they can diminish its fluorescence. However, when the material is separated by a certain distance from the nanoparticles, the fluorescence of the material increases again. In a cell culture model of oral squamous cell carcinoma, it was discovered that when gold nanoparticles were cultured like cells, the original autofluorescence of cancer cells was reduced by about $15 \% .{ }^{18}$ This phenomenon is known to occur due to the strong light absorption of nanoparticles.

\section{Surface-enhanced raman scattering}

Raman scattering is a phenomenon that when light with a specific frequency is irradiated to a molecule the scattered light transformed by the natural vibration energy of the molecule is generated. Since the generated scattered light represents the intrinsic properties of the molecule, the molecular structure of a material can be inferred.

The surface plasmon resonance of gold nanoparticles amplifies Raman scattering of adjacent molecules to generate surface-enhanced Raman scattering, and the Raman scattering generated at this time is amplified by several million times, enabling detection of cancer cells in in-vivo animal experiments. ${ }^{21}$

\section{USE OF GOLD NANOPARTICLES IN DRUG DELIVERY}

Gold nanoparticles of 10 to $140 \mathrm{~nm}$ in size injected intravenously have the property of gathering around a malignant tumor when immune system cannot recognize it, and this phenomenon is called an enhanced permeability and retention (EPR) effect. ${ }^{23}$ Malignant tumors create a large number of new blood vessels to supply the nutrients needed for rapid growth, but those new blood vessels created are more permeable than normal blood vessels because their morphology is immature. Small nano-sized particles can move through the walls of the immature and highly permeable blood vessels and are retained in the tumor due to reduced lymphatic drainage.

However, simple gold nanoparticles, cause an immune response and are removed by the reticuloendothelial system as soon as they enter the body. To keep the nanoparticles in the bloodstream for a long time, it is necessary to put a protective film around the nanoparticles using a polymer such as polyethylene glycol (PEG) so that the nanoparticles can be sent to the tumor through the EPR effect, and such a method is called 'Pegylation' .

Since gold easily binds to sulfur molecules, gold nanoparticles can easily bind to a wide variety of substances by utilizing the reducing power of the thiol group. Taking advantage of these properties, the toxic compound tumor necrosis factor (TNF) can be selectively transferred to the target site. ${ }^{3}$ In particular, when TNF is bound to pegylation of gold nanoparticles, it exhibits selective toxicity in tumors without damage to other normal organs, and tumor specificity is also increased by TNF ligands. ${ }^{24,25}$ Currently available tracer ligands are epidermal growth factor, ${ }^{26}$ folate, ${ }^{27}$ transferrin, ${ }^{28}$ and single-chain variable fragment. ${ }^{29-31}$

\section{PHOTOTHERMAL THERAPY}

Tumors are selectively destroyed by hyperthermia at about $41-47^{\circ} \mathrm{C}$ because their heat-resistant capacity is reduced due to inadequate blood supply compared to normal cells. The high temperature loosens the cell membrane and elicit irreversible cell destruction through protein denaturation. However, the hyperthermia methods used in the past have shown many limitations in selectively destroying only the tumor and preserving the surrounding normal tissues, so their application has been limited. $^{32}$

Along with the discovery of the laser, thermal treatment using a laser was attempted for clinical application. However, a laser beam with a strong and small beam size penetrated deeply into the tissue but was limited due to a large disadvantage of non-selectivity.

There is photodynamic therapy known as photochemotherapy, which started as a method to increase such a target-specificity. ${ }^{33-39}$ a photosensitizer that reacts to light of a specific wavelength in the visible or near-infrared region convert normal oxygen in the tissue into toxic and activated oxygen, which cause direct destruction of tumor cells and closure of surrounding blood vessels. However, the main limitation of photodynamic therapy is that the photosensitizer remains in the body for too long. During 
this period, the patient is very sensitive to light, so it must be blocked from light.

Photothermal therapy is a variation of photodynamic therapy, and its basic concept is similar to that of photodynamic therapy. When a photothermal material reacts to a specific wavelength, electrons present on the surface of the material become excited, and heat is generated in surrounding tissues by energy generated while the excited electrons are stabilized. Such the heat can be used to destroy tumor cells. Currently, the available photoabsorbers include indocyanine green, ${ }^{40,41}$ naphthalocyanines, ${ }^{32}$ and porphyrins coordinated with transition metals. ${ }^{42}$ However, such dye-based materials have a problem of losing fluorescence after the light irradiation.

Recently, with the development of nanotechnology, various nanoparticles have used for photothermal treatment. The light absorption of metallic nanoparticles is 4-5 times more than that of the conventional light-absorbing dyes. Such strong light absorption can reduce the destruction of surrounding normal tissues because it enables effective treatment using less energy lasers. In addition, the metal nanoparticles show high stability to light and do not lose the fluorescence unlike in the dyes. The metal nanoparticles currently in use include gold nanosphere, ${ }^{16,43-45}$ gold nanorod, ${ }^{11,46}$ gold nanoshell, $9,10,47,48$ Gold nanocage, ${ }^{49}$ carbon nanotube. ${ }^{50}$ The metal nanoparticles have shown strong light absorption in the visible and near-infrared regions, which is suitable for photothermal treatment. As described above, by adjusting the size, shape, and composition of the gold nanoparticles, the most energy can be absorbed in the visible and near-infrared regions. In particular, nanospheres, nanorods, and nanoshells are very useful because of their ease of manufacture, various applicability, and adjustable optical properties.

Since making colloidal gold for the first time, it has become possible to produce particles that can be sized, and there have been many studies on the relationship between these particles and light. Gold nanospheres create a strong surface plasmon resonance phenomenon in response to light in the visible light region. As the particle size increases, the wavelength of the reacting light moves to the longer side, and when the nanoparticles are fused or clumped together, they react to light in the near-infrared region. This concept has spurred great interest for research on gold nanoparticles, whose reaction frequency can be adjusted by varying nanoparticles size and shape. As a result, near-infrared rays that have higher transmittance in tissues can be used for photothermal treatment.

Gold nanoshell which is a modification of gold nanospheres, allows frequency adjustments. The gold nanoshell structure consists of a 100-200 nm silica core surrounded by a thin gold shell made of $5-20 \mathrm{~nm}$ gold. These nanoshells show strong light absorption and light scattering to near-infrared rays. ${ }^{51}$ This optical property can be adjusted according to the ratio of the thickness of the gold shell to the diameter of the silica core of the nanoshell, and as the ratio decreases, the wavelength responds to longer light. ${ }^{52}$

The discovery of gold nanoparticles, which can effectively generate heat with low-energy light in response to specific wavelengths, will be a major milestone in the use of photothermal treatment in cancer treatments. Considering that most cancers are deep-seated in the body, photothermal treatment using near-infrared rays is a promising option owing to its good tissue permeability and minimal damage to normal tissues. Near-infrared rays can penetrate approximately $10 \mathrm{~cm}$ inside the breast tissue and about $4 \mathrm{~cm}$ inside deep muscle tissues. ${ }^{53}$ Notably, the efficacy of nanoparticles in phototherapy is also dependent on the type of nanoparticles and light source. The method of transmission may vary depending on the tumor origin and site; it can be passed through a blood vessel or directly infused into the tumor to destroy the tumor cells or to irradiate the cancer cells that remain after surgery.

Although there are no controversies surrounding the method of light transmission, there are ongoing research on methods of selectively moving gold nanoparticles into tumors. Among the promising methods is the use of preengineered macrophages; macrophages are pre-engineered in vitro and act as vectors by ingesting nanoparticles and then latter moving them through the blood vessels into the tumor cells (Fig. 2). ${ }^{10,54-61}$ However, It is thought that the specificity of the delivery of nanoparticles can be enhanced by further studies on which substances among the chemokines secreted from tumor cells promote the chemotaxis of macrophages.

\section{APPLICATION IN THE FIELD OF RADIATION ONCOLOGY}

Gold has high radiation absorption capability providing an excellent platform for enhancing ionizing radiation. It has been reported that tumor radiation exposure increases by $200 \%$ or more with gold nanoparticles. ${ }^{62}$ Furthermore, other animal study demonstrated gold nanoparticles enhanced radiation therapy to have excellent therapeutic effects against tumors compared to the use of radiation therapy alone. ${ }^{16}$ Thus, the radiation therapy with gold nanoparticles may enhance the effect 


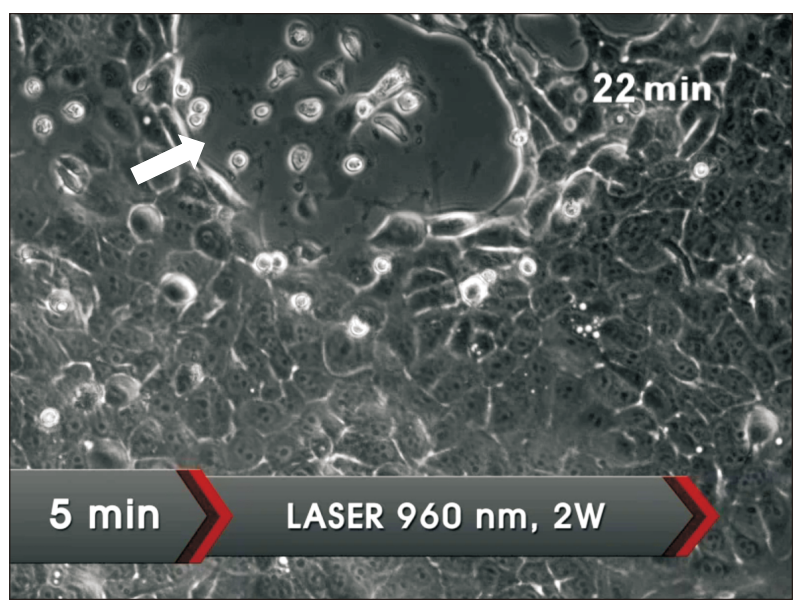

Fig. 2. Photothermal effect killing tumor cells. The tumor cells die around gold nanoshells-loading macrophages (arrow) by irradiating with near-infrared laser for 5 minutes.

of radiotherapy as well as achieve effective photothermal treatment. ${ }^{63}$

\section{POTENTIAL HAZARDS OF NANOPARTICLES}

The limitation of nanoparticles, which is expected to be applicable to diagnosis or treatment of various diseases, is that sufficient studies have not been conducted on the potential dangers of nanoparticles in vivo. These particles pose a risk of causing various lesions in the respiratory, cardiovascular and gastrointestinal systems. ${ }^{64}$

Because nanoparticles have a large surface area compared to their volume, they are very active and can induce various catalytic reactions. In addition, since it can easily move through the cell membrane, sufficient research should be conducted on the physiological action of the particles. In particular, although it is possible in animal experiments, studies on the dangers in humans in vivo are limited, so studies on this should be sufficiently conducted in the future.

\section{CONCLUSION}

The clinical application of nanoparticles with constant and adjustable optical features is expected to be very encouraging in the future. The development of a very sensitive short-term method that goes beyond several diagnostic techniques currently in use, or more tumorspecific chemotherapy, radiation therapy, and photothermal therapy can be applied as primary or auxiliary therapy. The possibility of nanoparticles acting as toxic substances in the body is still unresolved, but if the use of nanoparticles is expected to be superior in terms of effects by comparing the limitations of current treatments with the toxic effects Significant steps can be made in the diagnosis and treatment of many diseases, including head and neck cancer.

\section{CONFLICT OF INTEREST}

Seung-Kuk Baek is an editorial board member of the journal but was not involved in the review process of this manuscript. Otherwise, there is no conflict of interest to declare.

\section{FUNDING}

This research was supported by the Clinical Trial Center of Korea University Anam Hospital (11502411), the Korea Health Technlogy R\&D Project (HI14C0748) through the Korea Health Industry Development Institute (KHIDI) by the Ministry of Health \& Welfare, and the Basic Science Research Program through the National Research Foundation of Korea funded by the Ministry of Education (NRF2016R1D1A1A02937362, NRF-2018R1D1A1A09083263).

\section{REFERENCES}

1. El-Sayed MA. Some interesting properties of metals confined in time and nanometer space of different shapes. Acc Chem Res 2001;34:257-64.

2. West JL, Halas NJ. Engineered nanomaterials for biophotonics applications: improving sensing, imaging, and therapeutics. Annu Rev Biomed Eng 2003;5:285-92.

3. Paciotti GF, Myer L, Weinreich D, Goia D, Pavel N, McLaughlin RE, et al. Colloidal gold: a novel nanoparticle vector for tumor directed drug delivery. Drug Deliv 2004;11:169-83.

4. Jain KK. Nanotechnology-based drug delivery for cancer. Technol Cancer Res Treat 2005;4:407-16.

5. Wu X, Liu H, Liu J, Haley KN, Treadway JA, Larson JP, et al. Immunofluorescent labeling of cancer marker Her2 and other cellular targets with semiconductor quantum dots. Nat Biotechnol 2003;21:41-6.

6. Chan WC, Maxwell DJ, Gao X, Bailey RE, Han M, Nie S. Luminescent quantum dots for multiplexed biological detection and imaging. Curr Opin Biotechnol 2002;13:40-6.

7. Alivisatos P. The use of nanocrystals in biological detection. Nat Biotechnol 2004;22:47-52.

8. Sokolov K, Aaron J, Hsu B, Nida D, Gillenwater A, Follen M, et al. Optical systems for in vivo molecular imaging of cancer. Technol Cancer Res Treat 2003;2:491-504.

9. Hirsch LR, Stafford RJ, Bankson JA, Sershen SR, Rivera B, 
Price RE, et al. Nanoshell-mediated near-infrared thermal therapy of tumors under magnetic resonance guidance. Proc Natl Acad Sci U S A 2003;100:13549-54.

10. Baek SK, Makkouk AR, Krasieva T, Sun CH, Madsen SJ, Hirschberg H. Photothermal treatment of glioma; an in vitro study of macrophage-mediated delivery of gold nanoshells. J Neurooncol 2011;104:439-48.

11. Huang X, El-Sayed IH, Qian W, El-Sayed MA. Cancer cell imaging and photothermal therapy in the near-infrared region by using gold nanorods. J Am Chem Soc 2006;128:2115-20.

12. El-Sayed IH, Huang X, El-Sayed MA. Selective laser photo-thermal therapy of epithelial carcinoma using anti-EGFR antibody conjugated gold nanoparticles. Cancer Lett 2006;239:129-35.

13. Dickerson EB, Dreaden EC, Huang X, El-Sayed IH, Chu H, Pushpanketh S, et al. Gold nanorod assisted near-infrared plasmonic photothermal therapy (PPTT) of squamous cell carcinoma in mice. Cancer Lett 2008;269:57-66.

14. Niidome T, Yamagata M, Okamoto Y, Akiyama Y, Takahashi $H$, Kawano T, et al. PEG-modified gold nanorods with a stealth character for in vivo applications. J Control Release 2006;114:343-7.

15. Salem AK, Searson PC, Leong KW. Multifunctional nanorods for gene delivery. Nat Mater 2003;2:668-71.

16. Hainfeld JF, Slatkin DN, Smilowitz HM. The use of gold nanoparticles to enhance radiotherapy in mice. Phys Med Biol 2004;49:N309-15.

17. Hainfeld JF, Dilmanian FA, Zhong Z, Slatkin DN, Kalef-Ezra JA, Smilowitz HM. Gold nanoparticles enhance the radiation therapy of a murine squamous cell carcinoma. Phys Med Biol 2010;55:3045-59.

18. El-Sayed IH, Huang X, El-Sayed MA. Surface plasmon resonance scattering and absorption of anti-EGFR antibody conjugated gold nanoparticles in cancer diagnostics: applications in oral cancer. Nano Lett 2005;5:829-34.

19. Sokolov K, Follen M, Aaron J, Pavlova I, Malpica A, Lotan R, et al. Real-time vital optical imaging of precancer using antiepidermal growth factor receptor antibodies conjugated to gold nanoparticles. Cancer Res 2003;63:1999-2004.

20. Li PC, Wang CR, Shieh DB, Wei CW, Liao CK, Poe C, et al. In vivo photoacoustic molecular imaging with simultaneous multiple selective targeting using antibody-conjugated gold nanorods. Opt Express 2008;16:18605-15.

21. Qian X, Peng XH, Ansari DO, Yin-Goen Q, Chen GZ, Shin DM, et al. In vivo tumor targeting and spectroscopic detection with surface-enhanced Raman nanoparticle tags. Nat Biotechnol 2008;26:83-90.

22. Kneipp K, Kneipp H, Kneipp J. Surface-enhanced Raman scattering in local optical fields of silver and gold nanoaggregatesfrom single-molecule Raman spectroscopy to ultrasensitive probing in live cells. Acc Chem Res 2006;39:443-50.
23. Iyer AK, Khaled G, Fang J, Maeda H. Exploiting the enhanced permeability and retention effect for tumor targeting. Drug Discov Today 2006;11:812-8.

24. Goel R, Shah N, Visaria R, Paciotti GF, Bischof JC. Biodistribution of TNF-alpha-coated gold nanoparticles in an in vivo model system. Nanomedicine (Lond) 2009;4:401-10.

25. Pirollo KF, Chang EH. Does a targeting ligand influence nanoparticle tumor localization or uptake? Trends Biotechnol 2008;26:552-8.

26. de Bruin K, Ruthardt N, von Gersdorff K, Bausinger R, Wagner E, Ogris $M$, et al. Cellular dynamics of EGF receptor-targeted synthetic viruses. Mol Ther 2007;15:1297-305.

27. Hilgenbrink AR, Low PS. Folate receptor-mediated drug targeting: from therapeutics to diagnostics. J Pharm Sci 2005;94:2135-46.

28. Xu L, Pirollo KF, Tang WH, Rait A, Chang EH. Transferrinliposome-mediated systemic p53 gene therapy in combination with radiation results in regression of human head and neck cancer xenografts. Hum Gene Ther 1999;10:2941-52.

29. Dass CR, Choong PF. Selective gene delivery for cancer therapy using cationic liposomes: in vivo proof of applicability. J Control Release 2006;113:155-63.

30. Xu L, Tang WH, Huang CC, Alexander W, Xiang LM, Pirollo KF, et al. Systemic p53 gene therapy of cancer with immunolipoplexes targeted by anti-transferrin receptor scFv. Mol Med 2001;7:723-34.

31. Xu L, Huang CC, Huang W, Tang WH, Rait A, Yin YZ, et al. Systemic tumor-targeted gene delivery by anti-transferrin receptor scFv-immunoliposomes. Mol Cancer Ther 2002;1:337-46.

32. Huang X, Jain PK, El-Sayed IH, El-Sayed MA. Plasmonic photothermal therapy (PPTT) using gold nanoparticles. Lasers Med Sci 2008;23:217-28.

33. Wilson BC, Patterson MS. The physics of photodynamic therapy. Phys Med Biol 1986;31:327-60.

34. Daniell MD, Hill JS. A history of photodynamic therapy. Aust N Z J Surg 1991;61:340-8.

35. Henderson BW, Dougherty TJ. How does photodynamic therapy work? Photochem Photobiol 1992;55:145-57.

36. Ochsner M. Photophysical and photobiological processes in the photodynamic therapy of tumours. J Photochem Photobiol B 1997;39:1-18.

37. Dougherty TJ, Gomer CJ, Henderson BW, Jori G, Kessel D, Korbelik M, et al. Photodynamic therapy. J Natl Cancer Inst 1998;90:889-905.

38. Dolmans DE, Fukumura D, Jain RK. Photodynamic therapy for cancer. Nat Rev Cancer 2003;3:380-7.

39. Gold MH. Introduction to photodynamic therapy: early experience. Dermatol Clin 2007;25:1-4.

40. Chen WR, Adams RL, Heaton S, Dickey DT, Bartels KE, Nordquist RE. Chromophore-enhanced laser-tumor tissue photo- 
thermal interaction using an 808-nm diode laser. Cancer Lett 1995;88:15-9.

41. Chen WR, Adams RL, Bartels KE, Nordquist RE. Chromophoreenhanced in vivo tumor cell destruction using an 808-nm diode laser. Cancer Lett 1995;94:125-31.

42. Jori G, Spikes JD. Photothermal sensitizers: possible use in tumor therapy. J Photochem Photobiol B 1990;6:93-101.

43. Pitsillides CM, Joe EK, Wei $X$, Anderson RR, Lin CP. Selective cell targeting with light-absorbing microparticles and nanoparticles. Biophys J 2003;84:4023-32.

44. Zharov VP, Galitovskaya EN, Johnson C, Kelly T. Synergistic enhancement of selective nanophotothermolysis with gold nanoclusters: potential for cancer therapy. Lasers Surg Med 2005;37:219-26.

45. Huang X, Jain PK, El-Sayed IH, El-Sayed MA. Determination of the minimum temperature required for selective photothermal destruction of cancer cells with the use of immunotargeted gold nanoparticles. Photochem Photobiol 2006;82:412-7.

46. Huff TB, Tong L, Zhao Y, Hansen MN, Cheng JX, Wei A. Hyperthermic effects of gold nanorods on tumor cells. Nanomedicine (Lond) 2007;2:125-32.

47. O'Neal DP, Hirsch LR, Halas NJ, Payne JD, West JL. Photothermal tumor ablation in mice using near infrared-absorbing nanoparticles. Cancer Lett 2004;209:171-6.

48. Loo C, Lowery A, Halas N, West J, Drezek R. Immunotargeted nanoshells for integrated cancer imaging and therapy. Nano Lett 2005;5:709-11.

49. Hu M, Petrova H, Chen J, McLellan JM, Siekkinen AR, Marquez $M$, et al. Ultrafast laser studies of the photothermal properties of gold nanocages. J Phys Chem B 2006;110:1520-4.

50. Kam NW, O'Connell M, Wisdom JA, Dai H. Carbon nanotubes as multifunctional biological transporters and near-infrared agents for selective cancer cell destruction. Proc Natl Acad Sci U S A 2005;102:11600-5.

51. Prodan E, Radloff C, Halas NJ, Nordlander P. A hybridization model for the plasmon response of complex nanostructures. Science 2003;302:419-22.

52. Loo C, Lin A, Hirsch L, Lee MH, Barton J, Halas N, et al. Nanoshell-enabled photonics-based imaging and therapy of cancer. Technol Cancer Res Treat 2004;3:33-40.

53. Weissleder R. A clearer vision for in vivo imaging. Nat Biotechnol 2001;19:316-7.

54. Yang TD, Choi W, Yoon TH, Lee KJ, Lee JS, Han SH, et al. Realtime phase-contrast imaging of photothermal treatment of head and neck squamous cell carcinoma: an in vitro study of macrophages as a vector for the delivery of gold nanoshells. J Biomed Opt 2012;17:128003.

55. Yang TD, Choi W, Yoon TH, Lee KJ, Lee JS, Joo JH, et al. In vivo photothermal treatment by the peritumoral injection of macrophages loaded with gold nanoshells. Biomed Opt Express 2015; 7:185-93.

56. Yang TD, Park K, Kim HJ, Im NR, Kim B, Kim T, et al. In vivo photothermal treatment with real-time monitoring by optical fiber-needle array. Biomed Opt Express 2017;8:3482-92.

57. Valable S, Barbier EL, Bernaudin M, Roussel S, Segebarth C, Petit $E$, et al. In vivo MRI tracking of exogenous monocytes/ macrophages targeting brain tumors in a rat model of glioma. Neuroimage 2008;40:973-83.

58. Wu J, Yang S, Luo H, Zeng L, Ye L, Lu Y. Quantitative evaluation of monocyte transmigration into the brain following chemical opening of the blood-brain barrier in mice. Brain Res 2006;1098:79-85.

59. Owen MR, Byrne HM, Lewis CE. Mathematical modelling of the use of macrophages as vehicles for drug delivery to hypoxic tumour sites. J Theor Biol 2004;226:377-91.

60. Choi MR, Stanton-Maxey KJ, Stanley JK, Levin CS, Bardhan R, Akin D, et al. A cellular Trojan Horse for delivery of therapeutic nanoparticles into tumors. Nano Lett 2007;7:3759-65.

61. Dou H, Destache CJ, Morehead JR, Mosley RL, Boska MD, Kingsley J, et al. Development of a macrophage-based nanoparticle platform for antiretroviral drug delivery. Blood 2006; 108:2827-35.

62. Hainfeld JF, Dilmanian FA, Slatkin DN, Smilowitz HM. Radiotherapy enhancement with gold nanoparticles. J Pharm Pharmacol 2008;60:977-85.

63. Diagaradjane P, Shetty A, Wang JC, Elliott AM, Schwartz J, Shentu $\mathrm{S}$, et al. Modulation of in vivo tumor radiation response via gold nanoshell-mediated vascular-focused hyperthermia: characterizing an integrated antihypoxic and localized vascular disrupting targeting strategy. Nano Lett 2008;8:1492-500.

64. Medina C, Santos-Martinez MJ, Radomski A, Corrigan OI, Radomski MW. Nanoparticles: pharmacological and toxicological significance. Br J Pharmacol 2007;150:552-8.

How to cite this article: Baek SK. Clinical application of gold nanoparticles for diagnosis and treatment. Med Lasers 2021;10:61-67. https://doi.org/10.25289/ML.2021.10.2.61 